\title{
CONSUMO E RESÍDUOS ELETROELETRÔNICOS: A LOGÍSTICA REVERSA COMO INSTRUMENTO DO DESENVOLVIMENTO SUSTENTÁVEL
}

\author{
CONSUMPTION AND ELECTRONIC WASTE: REVERSE LOGISTIC AS \\ INSTRUMENT OF SUSTAINABLE DEVELOPMENT
}

\section{Camila Monteiro Santos Stohrer ${ }^{1}$ \\ Lisiane Ferreira Pieniz ${ }^{2}$}

SUMÁRIO: Introdução; 1. Da Sustentabilidade e do Desenvolvimento Sustentável; 2. O modelo atual de consumo e seus resíduos; 3. A Política Nacional de Resíduos Sólidos - Lei 12.305/2010; Considerações Finais; Referências das Fontes Citadas.

RESUMO: O atual modelo de consumo brasileiro reflete uma realidade mundial, qual seja a de que o homem não está preparado para lidar com os resíduos de sua vida cotidiana. A promulgação de uma Política Nacional de Resíduos Sólidos traz consigo instrumentos que, uma vez implementados, são de grande valia no gerenciamento da grande quantidade de resíduos sólidos gerada pela atividade de consumo. Desta feita, 0 artigo se propõe a analisar o conceito de Sustentabilidade e Desenvolvimento Sustentável, com o objetivo de identificar se o atual modelo de consumo brasileiro é sustentável quanto à geração e gestão de resíduos sólidos eletrônicos, bem como se o instrumento da logística reversa, presente na Política Nacional de Resíduos Sólidos, lei número 12.305/2010, tem conseguido alcançar seu objetivo de gerenciamento dos resíduos. Mediante utilização do Método Indutivo, o artigo conclui que os padrões de consumo praticados no Brasil são incompatíveis com o conceito de sustentabilidade, bem como identifica que a logística reversa dos eletroeletrônicos ainda não é uma realidade, não alcançando, portanto, seu objetivo.

\footnotetext{
${ }^{1}$ Mestre em Ciência Jurídica pela Universidade do Vale do Itajaí. Professora da disciplina de Direito Ambiental na Universidade do Vale do Itajaí, Campus Itajaí, Santa Catarina, Brasil. Advogada. Email: camila stohrer@univali.br

${ }^{2}$ Mestre em Ciência Jurídica pela Universidade do Vale do Itajaí. Professora do Escritório Modelo de Advocacia (EMA) na Universidade do Vale do Itajaí, Campus Itajaí, Santa Catarina, Brasil. Advogada. Email: lisiane.univali@univali.br
} 
STOHRER, Camila Monteira Santos; PIENIZ, Lisiane Ferreira. Consumo e resíduos eletroeletrônicos: a logística reversa como instrumento do desenvolvimento sustentável. Revista Eletrônica Direito e Política, Programa de Pós-Graduação Stricto Sensu em Ciência Jurídica da UNIVALI, Itajaí, v.10, n.1, edição especial de 2015. Disponível em: www.univali.br/direitoepolitica - ISSN 1980-7791.

Palavras-Chave: Consumo; Resíduos Sólidos; Sustentabilidade.

ABSTRACT: The current Brazilian consumption model reflects a worldwide reality: mankind is not prepared to deal the wastes of its everyday life. The proclamation of a National Solid Waste Policy brings along instruments which, once implemented, are of great value in management of the big amount of solid waste generated by the activity of consumption. Thus, this article aims to analyze the concept of Sustainability and Sustainable Development, with the purpose of identifying if the current Brazilian consumption model is sustainable regarding electronic waste generation, as well as observing if the instruments of the National Solid Waste Policy, Law number 12.305/2010, have been able to reach their goal on waste management through the use of the instrument of reverse logistic. Within the use of the Inductive Method, the article concludes that consumption patterns in Brazil are not compatible with the concept of sustainability, as well as identifies that reverse logistic of electronic waste is yet not a reality, and thus, does not reach its goal.

Keywords: Consumption; Solid Waste; Sustainability.

\section{INTRODUÇÃO}

A problemática ambiental contemporânea encontra motivação no modelo de produção e consumo adotado pelos países capitalistas. Em meio a uma enxurrada de apelos publicitários seduzindo o cidadão ao consumo, a geração de resíduos sólidos se apresenta como consequência inafastável no cenário apresentado.

Parte do papel do cientista jurídico ambiental é buscar alternativas adequadas à proteção do saudoso direito ao meio ambiente ecologicamente equilibrado, o qual, em virtude do excesso de resíduos sólidos eletrônicos gerados pelo padrão de consumo mencionado, acaba por ser prejudicado de maneira direta.

Desta feita, é objetivo do presente estudo verificar as alternativas legislativas já existentes no ordenamento jurídico brasileiro para a proteção do meio ambiente por intermédio da gestão dos resíduos sólidos, bem como identificar se o atual modelo de consumo existente no país corresponde aos ideais de desenvolvimento sustentável previstos na legislação. 
STOHRER, Camila Monteira Santos; PIENIZ, Lisiane Ferreira. Consumo e resíduos eletroeletrônicos: a logística reversa como instrumento do desenvolvimento sustentável. Revista Eletrônica Direito e Política, Programa de Pós-Graduação Stricto Sensu em Ciência Jurídica da UNIVALI, Itajaí, v.10, n.1, edição especial de 2015. Disponível em: www.univali.br/direitoepolitica - ISSN 1980-7791.

Ainda, o artigo se propõe, de maneira breve e sem o intuito de esgotar o tema, a analisar os mecanismos trazidos pela Política Nacional de Resíduos Sólidos e verificar sua efetiva aplicação na atualidade brasileira.

Para tanto, o artigo foi dividido em três temas centrais. Em um primeiro momento, trata da sustentabilidade e do desenvolvimento sustentável, elucidando seus conceitos. Posteriormente, analisa o atual modelo de consumo brasileiro, apresentando estatísticas a respeito da quantidade de resíduos sólidos eletrônicos produzida por um cidadão comum, bem como conceitos como obsolescência programada. Por fim, o artigo trata da Lei número 12.305/2010, Política Nacional de Resíduos Sólidos, identificando seus instrumentos e as principais dificuldades na sua efetivação.

Ao final, o artigo apresenta a relação entre o modelo de consumo adotado no Brasil, e a sua (in)sustentabilidade tendo em vista as dificuldades na aplicação da PNRS, principalmente quanto à implementação do instrumento da logística reversa.

\section{DA SUSTENTABILIDADE E DO DESENVOLVIMENTO SUSTENTÁVEL}

Muito se fala em sustentabilidade e em desenvolvimento sustentável, e, para aqueles que não se aprofundam nos estudos de ambos, os termos acabam sendo tidos como sinônimos. No entanto, os conceitos, ainda que complementares, não podem ser considerados idênticos, conforme se passa a explanar.

A realidade econômica global se baseia no crescimento e no desenvolvimento, e para isso requer recursos naturais. O uso indiscriminado destes recursos leva a uma sobrecarga do planeta, o qual não tem tempo hábil para repor aquilo que está sendo consumido. A tal fenômeno se dá o nome de Pegada Ecológica. ${ }^{3}$

3 Disponível em: http://www.wwf.org.br/natureza_brasileira/especiais/pegada_ecologica/o_que_ compoe_a_pegada/ Acesso em 10 de setembro de 2014. 
STOHRER, Camila Monteira Santos; PIENIZ, Lisiane Ferreira. Consumo e resíduos eletroeletrônicos: a logística reversa como instrumento do desenvolvimento sustentável. Revista Eletrônica Direito e Política, Programa de Pós-Graduação Stricto Sensu em Ciência Jurídica da UNIVALI, Itajaí, v.10, n.1, edição especial de 2015. Disponível em: www.univali.br/direitoepolitica - ISSN 1980-7791.

Já em 1972, durante a Conferência das Nações Unidas sobre o Meio Ambiente Humano, houve grande discussão a respeito da degradação ambiental, quando o alerta a respeito do uso desmedido dos recursos foi dado. ${ }^{4}$

Posteriormente, no ano de 1987, tem-se a publicação do Relatório de Brundtland, o qual pela primeira vez definiu desenvolvimento sustentável, e cuja definição vem sendo amplamente utilizada até hoje: "aquele que atende as necessidades das gerações atuais sem comprometer a capacidade das gerações futuras de atender a suas necessidades e aspirações." 5

No entanto, é necessário haver diferenciação entre os conceitos porquanto a ideia de desenvolvimento sustentável atrai para si a sustentabilidade apenas quando ao crescimento econômico, o que se apresenta como uma visão reducionista da pretensão verdadeira, qual seja a de criar um modo sustentável de vida. ${ }^{6}$

Mesmo porque, nas palavras de Leonardo Boff,

[...] sustentabilidade e desenvolvimento configuram uma contradição dos próprios termos. Eles têm lógicas que se autonegam: uma privilegia o indivíduo; a outra, o coletivo; uma enfatiza a competição, a outra, a cooperação; uma a evolução do mais apto, a outra a coevolução de todos juntos e inter-relacionados.

Paulo Affonso Leme Machado, entretanto, entende que é possível chegar ao conceito de sustentabilidade fazendo uso de dois critérios, num primeiro momento mediante análise dos efeitos da ação humana no tempo, para em seguida identificar quais efeitos desta conduta permanecerão no futuro, e que consequências terão. ${ }^{8}$

\footnotetext{
${ }^{4}$ BOFF, Leonardo. Sustentabilidade: o que é - o que não é. Petrópolis: Editora Vozes, 2012. P. 34.

${ }^{5}$ Apud BOFF, Leonardo. Sustentabilidade: o que é - o que não é. P. 34.

${ }^{6}$ BOFF, Leonardo. . Sustentabilidade: o que é - o que não é. P. 16.

${ }^{7}$ BOFF, Leonardo. . Sustentabilidade: o que é - o que não é. P. 45.

${ }^{8}$ MACHADO, Paulo Affonso Leme. Direito Ambiental Brasileiro. 20 ed. rev. atual. e ampl. São Paulo: Malheiros Editores, 2012. P. 71.
} 
STOHRER, Camila Monteira Santos; PIENIZ, Lisiane Ferreira. Consumo e resíduos eletroeletrônicos: a logística reversa como instrumento do desenvolvimento sustentável. Revista Eletrônica Direito e Política, Programa de Pós-Graduação Stricto Sensu em Ciência Jurídica da UNIVALI, Itajaí, v.10, n.1, edição especial de 2015. Disponível em: www.univali.br/direitoepolitica - ISSN 1980-7791.

Para que tais consequências sejam vistas pelo prisma do Direito Ambiental, é necessário, no entanto, que incidam sobre o conteúdo concernente ao meio ambiente. Destarte, para referido autor, a sustentabilidade, na acepção do termo, não necessariamente deve aparecer atrelada a questões ambientais.

Com o respeito que se deve ao autor, pensa-se que, em termos atuais, não existe mais a possibilidade de dissociar a questão ambiental do termo sustentabilidade, porquanto este já vem sendo empregando para além da semântica, levando o interlocutor a refletir sobre as questões ambientais e sobre a ação do homem e seus impactos no meio ambiente a cada vez que o termo é pronunciado.

Desta feita, faz-se necessário compreender o conceito de sustentabilidade com o viés ambiental que lhe é inerente. Na obra Direito do Ambiente, Edis Milaré ${ }^{9}$ dedica o primeiro capítulo a discutir a questão ambiental com eixo na sustentabilidade.

Para o autor, "Na atualidade que protagonizamos, grande parte da problemática global do Meio Ambiente - senão toda ela - gira em torno da sustentabilidade." ${ }^{10}$ Isto porque a questão central indaga sobre a possibilidade de a humanidade sobreviver e se sustentar no planeta.

Assim, a sustentabilidade seria a conjunção de dois fatores: um deles a questão ecológica, que diz respeito à capacidade natural de suporte, sem a qual os ecossistemas ficariam abalados. Também há de se falar em sustentabilidade social, qual seja a capacidade de sustentação da própria sociedade. Para discutir sustentabilidade, portanto, seria necessário sempre considerar a questão ecológica associada à questão social. ${ }^{11}$

Ademais, o que se deve buscar atualmente, no entendimento de Ignacy Sachs, é algo na linha do ecodesenvolvimento, pois que

\footnotetext{
${ }^{9}$ MILARÉ,Edis. Direito do Ambiente. 8 ed. rev. atual. e reform. São Paulo: Editora Revista dos Tribunais, 2013.

${ }^{10}$ MILARÉ, Edis. Direito do Ambiente. P. 45.

${ }^{11}$ Francisco P. de Melo Neto apud MILARÉ, Edis.Direito do Ambiente. P. 68-69.
} 
STOHRER, Camila Monteira Santos; PIENIZ, Lisiane Ferreira. Consumo e resíduos eletroeletrônicos: a logística reversa como instrumento do desenvolvimento sustentável. Revista Eletrônica Direito e Política, Programa de Pós-Graduação Stricto Sensu em Ciência Jurídica da UNIVALI, Itajaí, v.10, n.1, edição especial de 2015. Disponível em: www.univali.br/direitoepolitica - ISSN 1980-7791.

[...] não se alcançará uma sustentabilidade aceitável se não houver uma sensível diminuição das desigualdades sociais, a incorporação da cidadania como participação popular no jogo democrático, respeito às diferenças culturais e a introdução de valores éticos de respeito a toda vida e um cuidado permanente do meio ambiente. Preenchidos estes quesitos, criar-se-iam as condições de um ecodesenvolvimento sustentável. ${ }^{12}$

Deste modo, a sustentabilidade a que se refere o presente artigo está contida no conceito mais abrangente trazido por Leonardo Boff, qual seja a de que o ser humano e sua permanência na terra é apenas um dos aspectos a se considerar.

Passa-se à análise dos padrões de consumo existentes no Brasil, principalmente quanto à quantidade de resíduos sólidos eletrônicos gerados, de forma a identificar se ações tomadas em nível nacional podem ser consideradas sustentáveis. Para tanto, é crucial que a sustentabilidade seja vista de maneira holística, contemplando a permanência do homem no planeta atrelada à manutenção dos ecossistemas e da biodiversidade. ${ }^{13}$

\section{O MODELO ATUAL DE CONSUMO E SEUS RESÍDUOS}

Conforme disposto, o desenvolvimento sustentável alia as atividades que não esgotem nem degradem os recursos ambientais com o crescimento econômico. 0 desenvolvimento industrial deve crescer de forma paralela com a evolução do ser humano. Para tanto é necessário que se recicle mais e se polua menos. Também é imprescindível que se aumentem os reflorestamentos, sejam desenvolvidas formas de energias renováveis, bem como se recupere o que foi danificado na natureza através de ações humanas, enfim, que se promova o desenvolvimento sustentável. ${ }^{14}$

\footnotetext{
${ }^{12}$ BOFF, Leonardo. . Sustentabilidade: o que é - o que não é. P. 58.

${ }^{13}$ BOFF, Leonardo. Sustentabilidade: o que é - o que não é.

${ }^{14}$ BRASIL. Ana Maria. SANTOS, Fátima. Equilíbrio Ambiental e Resíduos na Sociedade Moderna. São Paulo: Faarte Editora, 2004.
} 
STOHRER, Camila Monteira Santos; PIENIZ, Lisiane Ferreira. Consumo e resíduos eletroeletrônicos: a logística reversa como instrumento do desenvolvimento sustentável. Revista Eletrônica Direito e Política, Programa de Pós-Graduação Stricto Sensu em Ciência Jurídica da UNIVALI, Itajaí, v.10, n.1, edição especial de 2015. Disponível em: www.univali.br/direitoepolitica - ISSN 1980-7791.

Nesse sentido as indústrias têm se aprimorado, implantando técnicas e recursos cada vez mais modernos, visando indiscutivelmente, a convivência harmônica com o meio ambiente, sem comprometer a qualidade de vida e a vida, que é o bem maior a ser resguardado.

Apesar do avanço tecnológico, que resultou na criação de uma diversidade de materiais disponíveis para produção e consumo, hoje em dia os produtos de todas as naturezas têm sito fabricados para terem uma duração reduzida, a fim de que sejam substituídos ou trocados por outros novos e com tecnologia mais avançada.

Este fenômeno, chamado obsolescência programada, se refere a produtos de fácil aquisição, mas que são projetados e fabricados para ter uma vida útil reduzida. Por esta razão, o consumidor sofre para dar a eles uma destinação final adequada e ainda se vê obrigado a comprar outro produto. ${ }^{15}$

A exemplo disso, cita-se a indústria de lâmpadas que na década de 1920, aplicou o conceito de "obsolescência programada" na linha de produção, visando reduzir a vida útil dos produtos para que o consumidor tivesse que trocá-lo com mais frequência. No entanto a ideia de diminuir o tempo de uso de produtos apareceu pela primeira vez em 1925, quando os principais fabricantes de lâmpadas da Europa e dos Estados Unidos, decidiram reduzir o tempo de duração de suas lâmpadas de duas mil e quinhentas para mil horas, objetivando o lucro das indústrias. ${ }^{16}$

No entanto somente na década de 1950 é que foi posta em prática a redução da vida útil dos produtos, sendo esta destacada e amplamente divulgada pela mídia

\footnotetext{
${ }^{15}$ BRAGA, Júlia. Obsolescência programada: o consumo exacerbado e o esgotamento de fontes naturais. Disponível em: http://www.goethe.de/ins/br/lp/kul/dub/umw/pt10282568.htm Acesso em 26 de setembro de 2014.

${ }^{16}$ COMPRAR, TIRAR, COMPRAR - La historia secreta de la Obsolescencia Programada. Direção de Cosima Dannoritzer. Espanha-França: Arte France, Televisión Española y Televisión de Catalunya.2010. Documentário. 52 min. Colorido. Disponível em: <http://www.youtube.com/watch?v=IkhwIHjBzjI > . Acesso em 18 de setembro de 2014.
} 
STOHRER, Camila Monteira Santos; PIENIZ, Lisiane Ferreira. Consumo e resíduos eletroeletrônicos: a logística reversa como instrumento do desenvolvimento sustentável. Revista Eletrônica Direito e Política, Programa de Pós-Graduação Stricto Sensu em Ciência Jurídica da UNIVALI, Itajaí, v.10, n.1, edição especial de 2015. Disponível em: www.univali.br/direitoepolitica - ISSN 1980-7791.

através da indução do desejo de consumir o novo, levando o consumidor a comprar por hábito, e não por necessidade. ${ }^{17}$

A obsolescência programada está intimamente relacionada à qualidade do produto, os quais eram fabricados para serem reutilizados e consertados e, desde a divulgação do conceito na indústria, são produzidos para que sejam substituídos assim que vencer seu prazo de validade, ou seja, o mais breve possível, pois certamente haverá no mercado outro produto mais moderno. ${ }^{18}$

Nesse sentido, cabe destacar que este modo de produção e de consumo mudou a relação do indivíduo com o produto, gerando inúmeras consequências ambientais e de consumo, levando o consumidor a atitudes precipitadas, pois não quer ficar desatualizado perante as ofertas de novos produtos com novos designs e novas tecnologias.

Os produtos tecnológicos são os mais atingidos pela obsolescência programada, considerando que, por exemplo, durante o período de garantia, os desktops e notebooks de alguns fabricantes funcionam normalmente. No entanto, após o fim desse prazo, passam a apresentar defeitos como superaquecimento ou esgotamento da bateria. Na quase totalidade dos casos o preço do conserto é tão alto que não vale a pena permanecer com o produto, levando o consumidor a adquirir novo produto.

Como o novo torna-se ultrapassado em pouco tempo, há sempre maior necessidade de se comprar para que se possa ter a sensação de pertencer a determinado grupo social e também de estar em dia com a tecnologia. ${ }^{19}$

Atualmente, conforme dados da Organização das Nações Unidas (ONU), o Brasil produz 0,5 (meio) kg de lixo eletrônico per capita ${ }^{20}$. Considerando que conforme

${ }^{17}$ BRAGA, Júlia. Obsolescência programada: o consumo exacerbado e o esgotamento de fontes naturais.

18 BAGGIO, Andreza Cristina; MANCIA, Karen Cristina Borio. A proteção do consumidor e o consumo sustentável: análise jurídica da extensão da durabilidade dos produtos e o atendimento ao princípio da confiança. Disponível em http://www.conpedi.org.br/manaus/arquivos/anais/brasilia/integra.pdf, <acesso em 27.set.214

19 BRAGA, Júlia. Obsolescência programada: o consumo exacerbado e o esgotamento de fontes naturais. 
STOHRER, Camila Monteira Santos; PIENIZ, Lisiane Ferreira. Consumo e resíduos eletroeletrônicos: a logística reversa como instrumento do desenvolvimento sustentável. Revista Eletrônica Direito e Política, Programa de Pós-Graduação Stricto Sensu em Ciência Jurídica da UNIVALI, Itajaí, v.10, n.1, edição especial de 2015. Disponível em: www.univali.br/direitoepolitica - ISSN 1980-7791.

- Instituto Brasileiro de Geografia e Estatística (IBGE) no seu último levantamento constatou que o Brasil tem 190 milhões de habitantes, conclui-se que os brasileiros são responsáveis pela produção de 95 mil toneladas de lixo eletrônico por ano.

Tamanha geração de resíduos é reflexo do atual modelo de consumo adotado pelos brasileiros, os quais, segundo explica a psiquiatra Ana Beatriz Barbosa Silva, compram para além de suprir suas necessidades diárias. As compras realizadas apenas com o intuito de consumir, cujos objetivos chegam à necessidade de aceitação pelos pares e adequação aos grupos sociais ${ }^{21}$, são as causadoras da quantidade imensa de resíduos eletrônicos gerados.

Este e-lixo é composto por televisões, celulares, aparelhos de som, aparelhos de fax, copiadoras, entre outros aparelhos de pequeno e grande porte, já obsoletos pelo tempo (desgaste) ou pelo lançamento de produtos com tecnologias mais modernas. Se descartados de maneira indevida, em locais não apropriados podem liberar na natureza um número considerável de elementos químicos tóxicos, causando danos irreparáveis para a natureza e para a vida. ${ }^{22}$

Destaca-se que a grande maioria das cidades brasileiras, ainda possui em sua estrutura a figura dos lixões - os quais devem ser substituídos por aterros sanitários por força da Política Nacional de Resíduos Sólidos - sendo estes o destino dos componentes eletrônicos ultrapassados. São nesses locais que são depositados de forma imprópria os aparelhos eletrônicos os quais apresentam na sua composição produtos químicos e metais, que na existência de eventuais

\footnotetext{
${ }^{20}$ PORTAL EXAME. Brasil produz muito lixo eletrônico, diz ONU. Portal da revista Exame. 2010. Disponível em: http://exame.abril.com.br/economia/meio-ambiente-e-energia/noticias/brasilemergente-mais-produz-lixo-eletronico-diz-onu-535153

${ }^{21}$ SILVA, Ana Beatriz Barbosa Silva. Mentes Consumistas - do consumismo à compulsão por compras. São Paulo: Editora Principium, 2014.

22 MATOS, Karen Maria da Costa; et al. Os impactos ambientais causados pelo lixo eletrônico e o uso da logística reversa para minimizar os efeitos causados ao meio ambiente. Disponível em: http://www.abepro.org.br/biblioteca/enegep2008_TN_STP_077_543_11709.pdf . Acesso em 26 de setembro de 2014.
} 
STOHRER, Camila Monteira Santos; PIENIZ, Lisiane Ferreira. Consumo e resíduos eletroeletrônicos: a logística reversa como instrumento do desenvolvimento sustentável. Revista Eletrônica Direito e Política, Programa de Pós-Graduação Stricto Sensu em Ciência Jurídica da UNIVALI, Itajaí, v.10, n.1, edição especial de 2015. Disponível em: www.univali.br/direitoepolitica - ISSN 1980-7791.

vazamentos contaminam o solo e causam riscos de incêndios, pondo em risco a população. ${ }^{23}$

Dessa forma o impacto ambiental causado pelo descarte do e-lixo em locais inapropriados é de grande relevância, devendo ser tratado com muito cuidado. Considerando que referido impacto leva a transformações em grande escala das características do meio, determinando a morte de seres vivos ou tornando difícil a sua sobrevivência em determinado ambiente, resultantes das atividades humanas que direta ou indiretamente afetem a saúde, a segurança e o bem estar da sociedade, é imprescindível, que bem se destine o lixo eletrônico, bem como sejam aplicadas as devidas políticas para tal destinação. ${ }^{24}$

Cabe ressaltar, entretanto que a Política Nacional de Resíduos Sólidos (PNRS), estabelece um conjunto de instrumentos para facilitar o retorno dos resíduos aos seus geradores, para que sejam tratados e reaproveitados em novos produtos. É a chamada logística reversa.

Entretanto, são raras as iniciativas adotadas no país para dar outro destino ao lixo tecnológico, já que, além da PNRS, a única regulamentação em nível federal vigente é a Resolução n. 257 de 30 de junho de 1999, do Conselho Nacional do Meio Ambiente - CONAMA, que estabelece limites para o uso de substâncias tóxicas em pilhas e baterias e imputa aos fabricantes a responsabilidade de ter sistemas para coleta destes materiais e encaminhá-los para reciclagem. ${ }^{25}$

Diante de uma situação tão alarmante, mudanças dos padrões de produção e consumo, de forma a diminuir o descarte desnecessário de toneladas de lixo eletrônico e tóxico no planeta, são essenciais para reverter esse quadro.

\footnotetext{
23 MATOS, Karen Maria da Costa; et al. Os impactos ambientais causados pelo lixo eletrônico e o uso da logística reversa para minimizar os efeitos causados ao meio ambiente.

${ }^{24}$ NETO, Alexandre Shigunov. CAMPOS, Lucila Maria de Souza. Shigunov, Tatiana. Fundamentos da Gestão Ambiental. Rio de Janeiro: Editora Ciência Moderna Ltda, 2009, P. 290.

25 BRASIL. Ministério do Meio Ambiente. Conselho Nacional de Meio Ambiente, CONAMA. Acesso em 29.set.2014. Resolução CONAMA no 257/99 de 26 de agosto de 1999. - In: Resoluções, 1999. Disponível em http://www.mma.gov.br Acesso em 26 de setembro de 2014.
} 
STOHRER, Camila Monteira Santos; PIENIZ, Lisiane Ferreira. Consumo e resíduos eletroeletrônicos: a logística reversa como instrumento do desenvolvimento sustentável. Revista Eletrônica Direito e Política, Programa de Pós-Graduação Stricto Sensu em Ciência Jurídica da UNIVALI, Itajaí, v.10, n.1, edição especial de 2015. Disponível em: www.univali.br/direitoepolitica - ISSN 1980-7791.

Salienta-se por fim a disparidade entre o poder de aquisição e a educação ambiental, pois ainda falta consciência quanto a produção de resíduos eletrônicos e os hábitos de consumo.

\section{A POLÍTICA NACIONAL DE RESÍDUOS SÓLIDOS - LEI 12.305/2010}

A Política Nacional de Resíduos Sólidos foi instituída pela lei 12.305/2010. Tal lei dispõe sobre os principais conceitos operacionais relativos à temática dos resíduos sólidos, apresenta objetivos e princípios, disponibiliza instrumentos e diretrizes, e versa sobre a responsabilização dos geradores e do poder público, trazendo verdadeiro arcabouço legislativo para a gestão de resíduos no Brasil. ${ }^{26}$

Assim, para a análise da efetividade na aplicação da referida Política, faz-se necessário compreender alguns conceitos por ela trazidos, de forma a limitar, uma vez mais, a amplitude do presente trabalho.

O primeiro conceito trazido pela lei é o de geradores de resíduos, que podem ser vislumbrados como "pessoas físicas ou jurídicas, de direito público ou privado, que geram resíduos sólidos por meio de suas atividades, nelas incluído o consumo" 27 (grifou-se). Como se vê, a atividade de consumo, objeto central do presente artigo, é identificada como fonte geradora de resíduos, e consoante se observou do item 2 do trabalho, tem impactos diretos no meio ambiente.

Os resíduos sólidos, do mesmo modo, têm sua conceituação prevista na referida legislação, e podem ser entendidos como

material, substância, objeto ou bem descartado resultante de atividades humanas em sociedade, a cuja destinação final se procede, se propõe proceder ou se está obrigado a proceder, nos estados sólido ou semissólido, bem como gases contidos em recipientes e líquidos cujas

\footnotetext{
${ }^{26}$ BRASIL. Lei n. 12.305 de 02 de agosto de 2010. Institui a Política Nacional de Resíduos Sólidos; altera a Lei no 9.605, de 12 de fevereiro de 1998; e dá outras providências. Disponível em: http://www.planalto.gov.br/ccivil_03/_ato2007-2010/2010/lei//12305.htm. Acesso em 20 de setembro de 2014.
}

${ }^{27}$ BRASIL. Lei n. 12.305 de 02 de agosto de 2010. Artigo 30, IX. 
STOHRER, Camila Monteira Santos; PIENIZ, Lisiane Ferreira. Consumo e resíduos eletroeletrônicos: a logística reversa como instrumento do desenvolvimento sustentável. Revista Eletrônica Direito e Política, Programa de Pós-Graduação Stricto Sensu em Ciência Jurídica da UNIVALI, Itajaí, v.10, n.1, edição especial de 2015. Disponível em: www.univali.br/direitoepolitica - ISSN 1980-7791.

particularidades tornem inviável o seu lançamento na rede pública de esgotos ou em corpos d'água, ou exijam para isso soluções técnica ou economicamente inviáveis em face da melhor tecnologia disponível. ${ }^{28}$

Dentre os princípios previstos no artigo $6^{\circ}$ da PNRS, é possível verificar o desenvolvimento sustentável, o qual, consoante tratado no item 1 deste artigo, vem sendo tratado como a possibilidade de crescer economicamente hoje sem prejudicar o amanhã.

Para a efetivação deste princípio, a PNRS apresenta um rol de instrumentos a serem aplicados, dentre os quais é possível destacar a logística reversa. Prevista no artigo $8^{\circ}$, inciso III da PNRS, a logística reversa é conceituada como

instrumento de desenvolvimento econômico e social
caracterizado por um conjunto de ações, procedimentos e
meios destinados a viabilizar a coleta e a restituição dos
resíduos sólidos ao setor empresarial, para
reaproveitamento, em seu ciclo ou em outros ciclos
produtivos, ou outra destinação final ambientalmente
adequada; ${ }^{29}$ (grifou-se)

Verifica-se que a palavra-chave do conceito de logística reversa é a restituição ao setor empresarial. No caso dos resíduos sólidos eletrônicos, tal instrumento não é de aplicação facultativa, consoante se extrai do artigo 33 da PNRS

Art. 33. São obrigados a estruturar e implementar sistemas de logística reversa, mediante retorno dos produtos após o uso pelo consumidor, de forma independente do serviço público de limpeza urbana e de manejo dos resíduos sólidos, os fabricantes, importadores, distribuidores e comerciantes de: [...]VI - produtos eletroeletrônicos e seus componentes. ${ }^{30}$

Diante de tal obrigação, o que se verifica é que o setor empresarial necessitará de auxílio na captação destes componentes disponibilizados no mercado, pelo que o mesmo artigo estabelece que cabe aos consumidores efetuar a devolução

\footnotetext{
${ }^{28}$ BRASIL. Lei n. 12.305 de 02 de agosto de 2010. Artigo 30, XVI.

${ }^{29}$ BRASIL. Lei n. 12.305 de 02 de agosto de 2010. Artigo 30, XII.

${ }^{30}$ BRASIL. Lei n. 12.305 de 02 de agosto de 2010.
} 
STOHRER, Camila Monteira Santos; PIENIZ, Lisiane Ferreira. Consumo e resíduos eletroeletrônicos: a logística reversa como instrumento do desenvolvimento sustentável. Revista Eletrônica Direito e Política, Programa de Pós-Graduação Stricto Sensu em Ciência Jurídica da UNIVALI, Itajaí, v.10, n.1, edição especial de 2015. Disponível em: www.univali.br/direitoepolitica - ISSN 1980-7791.

dos materiais ${ }^{31}$, tendo-se em conta a disponibilização de pontos de coleta pelas empresas.

Tal incumbência se dá pela estipulação pela PNRS da responsabilidade pelo ciclo de vida dos produtos, a qual é imposta aos fornecedores e consumidores, com vistas a minimizar os impactos ambientais oriundos do consumo. ${ }^{32}$

No entanto, a prática tem demonstrado o contrário. Há diversos desafios na implementação do sistema de logística reversa, dentre os quais se destaca a previsão legal de que cabe aos fornecedores o encargo de implementação.

Ainda é possível destacar outros desafios, quais sejam os conflitos de interesses entre as empresas que disponibilizam os produtos novos e aquelas que reutilizam os materiais residuais, porquanto poderiam ofertar produtos de qualidade semelhante com preço reduzido. ${ }^{33}$

Outra dificuldade importante a ser considerada é o custo da logística reversa, pois os custos com coleta, transporte e manuseio são muito elevados. ${ }^{34}$ Ademais, a complexidade na composição dos produtos eletrônicos dificulta a separação dos componentes, encarecendo ainda mais seu processamento. ${ }^{35}$

31 § 30 Sem prejuízo de exigências específicas fixadas em lei ou regulamento, em normas estabelecidas pelos órgãos do Sisnama e do SNVS, ou em acordos setoriais e termos de compromisso firmados entre o poder público e o setor empresarial, cabe aos fabricantes, importadores, distribuidores e comerciantes dos produtos a que se referem os incisos II, III, V e VI ou dos produtos e embalagens a que se referem os incisos I e IV do caput e o $\S 10$ tomar todas as medidas necessárias para assegurar a implementação e operacionalização do sistema de logística reversa sob seu encargo, consoante o estabelecido neste artigo, podendo, entre outras medidas: [...] II - disponibilizar postos de entrega de resíduos reutilizáveis e recicláveis; [...] § 40 Os consumidores deverão efetuar a devolução após o uso, aos comerciantes ou distribuidores, dos produtos e das embalagens a que se referem os incisos I a VI do caput, e de outros produtos ou embalagens objeto de logística reversa, na forma do $\S 10$.

32 BRASIL. Lei n. 12.305 de 02 de agosto de 2010. Art. 30, XVII.

33 LEITE, Paulo Roberto. Desafios da Logística Reversa de pós-consumo no Brasil. Disponível em: http://www.clrb.com.br/site/noticias.asp?id=218 Acesso em 20 de setembro de 2014.

34 LEITE, Paulo Roberto. Desafios da Logística Reversa de pós-consumo no Brasil.

35 BRASIL. Agência Brasileira De Desenvolvimento Industrial. Logística Reversa de Equipamentos Eletroeletrônicos. Análise da viabilidade técnica e econômica. Disponível em http://www.desenvolvimento.gov.br/arquivos/dwnl_1362058667.pdf Acesso em 20 de setembro de 2014. P. 17. 
STOHRER, Camila Monteira Santos; PIENIZ, Lisiane Ferreira. Consumo e resíduos eletroeletrônicos: a logística reversa como instrumento do desenvolvimento sustentável. Revista Eletrônica Direito e Política, Programa de Pós-Graduação Stricto Sensu em Ciência Jurídica da UNIVALI, Itajaí, v.10, n.1, edição especial de 2015. Disponível em: www.univali.br/direitoepolitica - ISSN 1980-7791.

Para a Agência Brasileira de Desenvolvimento Industrial ${ }^{36}$

O grande desafio da logística reversa reside no custo associado à operacionalização do sistema em um país de extensão continental e com suas particulares complexidades logísticas. É sabido que qualquer sistema que seja estabelecido incorrerá em maiores dispêndios, ora tratados como custos quando apreciados sob a ótica puramente econômica, ora encarados com investimento necessário para um mundo sustentável.

Os referidos custos, no entanto, não podem ser vistos como uma opção ao setor produtivo. Sabe-se que, consoante preceitua o artigo 225 da Constituição Federal ${ }^{37}$, é dever do Poder Público e de toda a coletividade a proteção das condições para a manutenção do meio ambiente ecologicamente equilibrado.

No conceito de coletividade é possível incluir com tranquilidade os produtores de eletroeletrônicos, os quais, por força inclusive do Princípio Poluidor-Pagador ${ }^{38}$, deveriam internalizar os custos sociais de seu produto. Parece evidente a relação entre a geração dos resíduos e os custos sociais do produto, porquanto os resíduos que permanecem no meio ambiente comprometem a qualidade ambiental, que é direito difuso.

Desta feita, verifica-se que não é convincente a argumentação de que os custos da logística reversa têm sido o maior empecilho para a sua implementação. 0 que se faz necessário é a atuação do Poder Público de forma a reforçar os postulados da PNRS, visando garantir que cada produtor abra seus canais de comunicação com o consumidor.

\section{CONSIDERAÇÕES FINAIS}

A pesquisa realizada teve como objetivo identificar se o atual modelo de consumo brasileiro é sustentável quanto à geração e gestão de resíduos sólidos

36 BRASIL. Agência Brasileira De Desenvolvimento Industrial. Logística Reversa de Equipamentos Eletroeletrônicos. Análise da viabilidade técnica e econômica. P. 17.

${ }^{37}$ BRASIL. Constituição da República Federativa do Brasil. Brasília, DF: Senado, 1988.

38 MACHADO, Paulo Affonso Leme. Direito Ambiental Brasileiro. P. 93-97. 
STOHRER, Camila Monteira Santos; PIENIZ, Lisiane Ferreira. Consumo e resíduos eletroeletrônicos: a logística reversa como instrumento do desenvolvimento sustentável. Revista Eletrônica Direito e Política, Programa de Pós-Graduação Stricto Sensu em Ciência Jurídica da UNIVALI, Itajaí, v.10, n.1, edição especial de 2015. Disponível em: www.univali.br/direitoepolitica - ISSN 1980-7791.

eletrônicos, bem como se o instrumento da logística reversa, presente na Política Nacional de Resíduos Sólidos, lei número 12.305/2010, tem conseguido alcançar seu objetivo de gerenciamento dos resíduos.

O que se observou no decorrer da pesquisa é que o brasileiro está seduzido pelo modelo de consumo pautado na obsolescência programada, através do qual os produtos são descartados tão logo surjam novos produtos mais atraentes no mercado.

O fato de adquirir novos produtos sem que os anteriores estejam, de fato, inutilizados, faz com que uma grande quantidade de resíduos seja lançada no meio ambiente com frequência, impactando negativamente à natureza.

Os aparelhos eletrônicos, em virtude dos constantes avanços tecnológicos, são adquiridos com habitualidade preocupante, dando ensejo a novos descartes. Tais aparelhos têm composição complexa, possuindo, diversas vezes, até mesmo metais pesados em sua estrutura.

O que se verifica é que os consumidores, sem refletir sobre os impactos de suas ações, contribuem indiscriminadamente para a geração de resíduos, porquanto não vislumbram os impactos a longo prazo deste padrão desmedido.

Assim, conclui-se que os padrões de consumo adotados no Brasil não podem ser considerados sustentáveis, pois o conceito de sustentabilidade adotado na pesquisa preceitua a necessidade de se verificar a possibilidade de permanência do homem no planeta, bem como a manutenção dos ecossistemas e da biodiversidade.

A geração de resíduos eletrônicos, nas proporções apresentadas na pesquisa, não pode ser considerada sustentável visto que seu impacto ambiental não é controlado, dando ensejo a um desequilíbrio ecológico latente.

Por este motivo se faz necessária a atuação do Poder Público para criar mecanismos legais para que os produtores se vejam obrigados a retirar de circulação aqueles componentes que não mais são utilizados pelo consumidor. 
STOHRER, Camila Monteira Santos; PIENIZ, Lisiane Ferreira. Consumo e resíduos eletroeletrônicos: a logística reversa como instrumento do desenvolvimento sustentável. Revista Eletrônica Direito e Política, Programa de Pós-Graduação Stricto Sensu em Ciência Jurídica da UNIVALI, Itajaí, v.10, n.1, edição especial de 2015. Disponível em: www.univali.br/direitoepolitica - ISSN 1980-7791.

No Brasil, tal mecanismo é o instrumento da logística reversa, a qual preceitua a responsabilidade do fornecedor de recolher do mercado os produtos que se tornaram resíduos.

Tal responsabilidade é reforçada pela previsão, no mesmo texto legal, da responsabilidade compartilhada pelo ciclo de vida do produto, a qual estende ao consumidor parte da incumbência de impedir que os resíduos sólidos sejam destinados diretamente no ambiente, sem o correto tratamento.

Entretanto, não obstante a previsão da Carta Magna e até mesmo do Princípio do Poluidor-Pagador, o que se verifica na prática é a inércia do setor industrial para a implantação dos canais de comunicação para com o consumidor, de forma a instituir de vez por todas seu sistema de logística reversa.

Os argumentos mais corriqueiros de que o custo de implantação deste sistema é muito elevado devem ser desconsiderados, haja vista que é dever de todos a proteção da qualidade ambiental, condição essencial, inclusive, para a garantia de permanência do homem na Terra.

Por fim, salienta-se que a Terra é um planeta com recursos finitos. Como já disse Serge Latouche, "aquele que crê que o crescimento econômico infinito é compatível com um planeta finito, é um tolo." ${ }^{139}$

\section{REFERÊNCIAS DAS FONTES CITADAS}

BAGGIO, Andreza Cristina; MANCIA, Karen Cristina Borio. A proteção do consumidor e o consumo sustentável: análise jurídica da extensão da durabilidade dos produtos e o atendimento ao princípio da confiança. Disponível em: <http://www.conpedi.org.br/manaus/arquivos/anais/brasilia/integra.pdf> Acesso em 27.set. 214

39 In: COMPRAR, TIRAR, COMPRAR - La historia secreta de la Obsolescencia Programada 
STOHRER, Camila Monteira Santos; PIENIZ, Lisiane Ferreira. Consumo e resíduos eletroeletrônicos: a logística reversa como instrumento do desenvolvimento sustentável. Revista Eletrônica Direito e Política, Programa de Pós-Graduação Stricto Sensu em Ciência Jurídica da UNIVALI, Itajaí, v.10, n.1, edição especial de 2015. Disponível em: www.univali.br/direitoepolitica - ISSN 1980-7791.

BRAGA, Júlia. Obsolescência programada: o consumo exacerbado e o esgotamento de fontes naturais. Disponível em: <http://www.goethe.de/ins/br/lp/kul/dub/umw/pt10282568.htm> Acesso em 26 de setembro de 2014.

BOFF, Leonardo. Sustentabilidade: o que é - o que não é. Petrópolis: Editora Vozes, 2012.

BRASIL. Agência Brasileira De Desenvolvimento Industrial. Logística Reversa de Equipamentos Eletroeletrônicos. Análise da viabilidade técnica e econômica.

<http://www.desenvolvimento.gov.br/arquivos/dwnl_1362058667.pdf> Acesso em 20 de setembro de 2014.

BRASIL, Ana Maria; SANTOS, Fátima. Equilíbrio Ambiental e Resíduos na Sociedade Moderna. São Paulo: Faarte Editora, 2004.

BRASIL. Constituição da República Federativa do Brasil. Brasília, DF: Senado, 1988.

BRASIL. Lei n. 12.305 de 02 de agosto de 2010. Institui a Política Nacional de Resíduos Sólidos; altera a Lei no 9.605, de 12 de fevereiro de 1998; e dá outras providências. Disponível em: <http://www.planalto.gov.br/ccivil_03 /_ato2007-2010/2010/lei/l12305.htm>. Acesso em 20 de setembro de 2014.

BRASIL. Ministério do Meio Ambiente. Conselho Nacional de Meio Ambiente, CONAMA. Acesso em 29.set.2014. Resolução CONAMA no 257/99 de 26 de agosto de 1999. - In: Resoluções, 1999. Disponível em <http://www.mma.gov.br> Acesso em 26 de setembro de 2014.

COMPRAR, TIRAR, COMPRAR - La historia secreta de la Obsolescencia Programada. Direção de Cosima Dannoritzer. Espanha-França: Arte France, Televisión Española y Televisión de Catalunya.2010. Documentário. 52 min. Colorido. Disponível em: <http://www.youtube.com/watch?v=IkhwIHjBzjI>. Acesso em 18 de setembro de 2014. 
STOHRER, Camila Monteira Santos; PIENIZ, Lisiane Ferreira. Consumo e resíduos eletroeletrônicos: a logística reversa como instrumento do desenvolvimento sustentável. Revista Eletrônica Direito e Política, Programa de Pós-Graduação Stricto Sensu em Ciência Jurídica da UNIVALI, Itajaí, v.10, n.1, edição especial de 2015. Disponível em: www.univali.br/direitoepolitica - ISSN 1980-7791.

LEITE, Paulo Roberto. Desafios da Logística Reversa de pós-consumo no Brasil. Disponível em: <http://www.clrb.com.br/site/noticias.asp?id=218> Acesso em 20 de setembro de 2014.

MACHADO, Paulo Affonso Leme. Direito Ambiental Brasileiro. 20 ed. rev. atual. e ampl. São Paulo: Malheiros Editores, 2012.

MATOS, Karen Maria da Costa; et al. Os impactos ambientais causados pelo lixo eletrônico e o uso da logística reversa para minimizar os efeitos causados ao meio ambiente. Disponível em: <http://www.abepro.org.br/biblioteca/enegep2008_TN_STP_077_543_11709.pd f> Acesso em 26 de setembro de 2014.

MILARÉ, Edis. Direito do Ambiente. 8 ed. rev. atual. e reform. São Paulo: Editora Revista dos Tribunais, 2013.

NETO, Alexandre Shigunov. CAMPOS, Lucila Maria de Souza. Shigunov, Tatiana. Fundamentos da Gestão Ambiental. Rio de Janeiro: Editora Ciência Moderna Ltda, 2009, P. 290.

PORTAL EXAME. Brasil produz muito lixo eletrônico, diz ONU. Portal da revista Exame. 2010. Disponível em: <http://exame.abril.com.br/economia/meioambiente-e-energia/noticias/brasil-emergente-mais-produz-lixo-eletronico-dizonu-535153>

SILVA, Ana Beatriz Barbosa Silva. Mentes Consumistas - do consumismo à compulsão por compras. São Paulo: Editora Principium, 2014.

WORLD WILD LIFE FOUNDATION. Disponível em: <http://www.wwf.org.br/natureza_brasileira/especiais/pegada_ ecologica/o_que_compoe_a_pegada/> Acesso em 10 de setembro de 2014.

Submetido em: Setembro/2014

Aprovado em: Outubro/2014 